\title{
Correction to: Take Nothing for Granted: Downward Social Comparison and Counterfactual Thinking Increase Adolescents' State Gratitude for the Little Things in Life
}

\section{Elena Gabriela Nicuță ${ }^{1}$ Ticu Constantin ${ }^{1}$}

Published online: 17 August 2021

(C) Springer Nature B.V. 2021

\section{Correction to: Journal of Happiness Studies https://doi.org/10.1007/s10902-021-00382-5}

We wish to mention that Elena Gabriela Nicuță and Ticu Constantin share co-first authorship of this article. The initial version of the paper did not include this statement, which we believe is important, because it properly acknowledges the equal contribution of the second author.

Publisher's Note Springer Nature remains neutral with regard to jurisdictional claims in published maps and institutional affiliations.

The original article can be found online at https://doi.org/10.1007/s10902-021-00382-5.

Elena Gabriela Nicuță

gabriela.nicuta@yahoo.com

Ticu Constantin

1 Faculty of Psychology and Education Sciences, Alexandru Ioan Cuza University of Iasi, Iasi, Romania 